\title{
Berberine Inhibits the Adhesion of Candida albicans to Vaginal Epithelial Cells
}

\author{
Ting Zhao ${ }^{1,2,3}$, Kang Zhang ${ }^{1,2,3}$, Gaoxiang Shi ${ }^{1,2,3}$, Kelong Ma ${ }^{1,2,3}$, Benfan Wang ${ }^{1,2,3}$, \\ Jing Shao ${ }^{1,2,3}$, Tianming Wang ${ }^{1,2,3 *}$ and Changzhong Wang ${ }^{1,2,3 *}$
}

${ }^{1}$ Department of Pathogenic Biology and Immunology, College of Integrated Chinese and Western Medicine (College of Life Science), Anhui University of Chinese Medicine, Hefei, China, ${ }^{2}$ Institute of Integrated Traditional Chinese and Western Medicine, Anhui University of Chinese Medicine, Hefei, China, ${ }^{3}$ Anhui Province Key Laboratory of Chinese Medicinal Formula, Hefei, China

\section{OPEN ACCESS}

Edited by:

Ligia Salgueiro,

University of Coimbra, Portugal

Reviewed by:

Eugénia Pinto,

University of Porto, Portugal

Monica Zuzarte,

University of Coimbra, Portugal

Maria Elisa Rodrigues,

University of Minho, Portugal

*Correspondence:

Tianming Wang

wtm1818@163.com

Changzhong Wang

ahwcz63@163.com

Specialty section:

This article was submitted to

Ethnopharmacology,

a section of the journal

Frontiers in Pharmacology

Received: 14 November 2021 Accepted: 07 February 2022 Published: 28 February 2022

Citation:

Zhao T, Zhang K, Shi G, Ma K, Wang $B$, Shao J, Wang T and Wang $C$ (2022) Berberine Inhibits the Adhesion of Candida albicans to Vaginal Epithelial Cells.

Front. Pharmacol. 13:814883. doi: 10.3389/fphar.2022.814883
Vulvovaginal candidiasis (VC) is an inflammatory disease of the vagina mainly caused by Candida albicans (C. albicans), which affects around three-quarters of all women during their reproductive age. Although some antifungal drugs such as azoles have been applied clinically for many years, their therapeutic value is very limited due to the emergence of drug-resistant strains. Previous studies have shown that the adhesion of $C$. albicans to vaginal epithelial cells is essential for the pathogenesis of WC. Therefore, preventing the adhesion of $C$. albicans to vaginal epithelial cells may be one of the most effective strategies for the treatment of WC. Berberine (BBR) is a biologically active herbal alkaloid that was used to treat WC. However, so far, its mechanism has remained unclear. This study shows BBR significantly inhibits the adhesion of $C$. albicans to vaginal epithelial cells by reducing the expressions of ICAM-1, mucin1, and mucin4 in vaginal epithelial cells, which play the most important role in modulating the adhesion of $C$. albicans to host cells, and balancing IL-2 and IL-4 expressions, which play a key effect on regulating the inflammatory response caused by $C$. albicans infection. Hence, our findings demonstrate that BBR may be a potential therapeutic agent for WC by interfering with the adhesion of $C$. albicans to vaginal epithelial cells and represents a new pathway for developing antifungal therapies agents from natural herbs.

Keywords: Berberine, Candida albicans, vaginal epithelial cells, vulvovaginal candidiasis, adhesion

\section{INTRODUCTION}

Candida albicans, a yeast-hypha dimorphic fungus, is widely found in the vagina, gastrointestinal tract, oral cavity, and on skin surface (Richardson et al., 2019), which easily results in opportunistic infection under certain circumstances and causes diseases such as Vulvovaginal Candidiasis (VVC). Adhesion of C. albicans to host cells is a key link for the opportunistic infection caused by this fungus (Mayer et al., 2013; Wu et al., 2020), which makes it prone to survive in the vagina, oral cavity, or other body parts (Krachler and Orth 2013). Multiple mechanisms are involved in the regulation of this adhesion. Studies have shown that C. albicans infection can stimulate vaginal epithelial cells to highly express adhesion molecules, such as ICAM-1, mucin1, and mucin4 (Moncla et al., 2016; Mikamo et al., 2018). Apparently, these increasingly regulatory molecules can create a favorable microenvironment for the colonization of C. albicans and the following disorders of local immune homeostasis. 
Therefore, reducing these adhesion molecules may block adhesion of C. albicans to host cells and protect the host from diseases caused by the opportunistic fungal infection.

VVC is an infectious disease of the female reproductive tract mainly caused by C. albicans, which can affect up to $75 \%$ of women of child-bearing age. The occurrence of VVC is related to the crucial virulence factors of $C$. albicans, such as secreted aspartyl proteinases (Sap), lipases (Lip), phospholipases (PL), candidalysin, morphological transition, and biofilm formation (Richardson et al., 2018; Willems et al., 2020). On the other hand, the virulence of $C$. albicans also depends on host immune status, especially the immune defense function of vaginal epithelial cells (Luan et al., 2020). C. albicans interacts with epithelial cells through adhesins on the cell wall (Martin et al., 2018). Epithelial cells provide the surface area that enables the initial adhesion of C. albicans. Under physiological conditions, this pathogen-host interaction, over long-term evolution, allows $C$. albicans and the host cells to adapt to each other without causing any disease. However, when the damaging effect of $C$. albicans exceeds the protective effect of the vaginal mucosal barrier, the impaired balance between C. albicans and the host may lead to infection. The adhesion of C. albicans to vaginal mucosal epithelial cells is known to be the initial step for the onset of VVC. Therefore, the inhibition of $C$. albicans adhesion and the protection of vaginal mucosal epithelial cells may be a potential strategy that prevents the VVC occurrence and development. Conventional antifungal drugs, such as fluconazole and echinocandin, mainly target the cell wall or cell membrane, so as to inhibit or even kill fungi, rather than to block fungal adhesion to host cells (Eschenauer, et al., 2015). Some reported that $C$. albicans biofilms could be inhibited by these drugs in vitro, but not in the setting of VVC model (Maiolo et al., 2014; Pesee et al., 2016). Given adhesion as the initial stage of biofilm formation, the drugs mentioned above might also interfere with adhesion to a certain extent, but there is still a lack of sufficient evidence in this regard.

Although some antifungal drugs such as azoles have been applied clinically for many years, the inherent resistance of C. albicans to these agents limited their therapeutic values (Sobel and Sobel 2018). In addition, these drugs also have side effects, such as liver toxicity. Hence, searching for new antifungal compounds with relatively low toxicity from natural herbs is an alternative pathway to develop new antifungal agents or therapies.

Berberine (BBR), a quaternary ammonium compound, is the most abundant bioactive component found in traditional Chinese herbs Coptis chinensis Franch [Ranunculaceae] and Phellodendron chinense C.K.Schneid. [Rutaceae]. It has been applied clinically to treat bacterial diarrhea, diabetes, and other diseases. Studies have shown that BBR can function as an antibacterial, antifungal, antiinflammatory, immunomodulatory, and even anti-cancer agent (Zhang et al., 2010; Li et al., 2014; Pirillo and Catapano 2015; Wang et al., 2018). Among them, the antifungal mechanism of BBR may involve the down-regulation of some key genes related to the integrity of $C$. albicans cell wall after treatment with this compound, such as the hypha-specific gene ECE1 related to the morphological transformation of C. albicans (Huang et al., 2020) and the genes FKS1 and FKS2 related to the synthesis of $\beta$-glucan components of C. albicans (Yang et al., 2021). Although BBR is reported to have inhibitory effects on C. albicans, to some extent, the detailed mechanism remain unknown (Xie et al., 2020).

In this study, whether BBR is able to suppress VVC pathogenesis by interfering with the interaction between $C$. albicans and host vaginal epithelial cells is investigated. Our results show that BBR significantly inhibits the adhesion of $C$. albicans to vaginal epithelial cells by decreasing the expression of ICAM-1, mucin1, and mucin 4 in cells and balancing IL-2 and IL4 expression during inflammation and shows its potential therapeutic value on VVC. The characterization of the herbal compound involved in the regulation of adhesion in VVC pathogenesis may lead to novel anti-fungal therapies that could significantly improve treatment for VVC reducing the public health burden of such diseases.

\section{MATERIALS AND METHODS}

\section{Yeast Strain Culture}

Candida albicans SC5314 was kindly provided by Professor Jiang Yuanying from the College of Pharmacy, Second Military Medical University (Shanghai, China). The glycerol-preserved fungal strain taken out from the $-80^{\circ} \mathrm{C}$ refrigerator was initially streaked onto Sabouraud's agar. By using a single colony, the strain was routinely inoculated for three generations in Sabouraud's agar plates. The strain was then activated and propagated in liquid Sabouraud medium (HopeBio-Tech Co., Qingdao, China) at $37^{\circ} \mathrm{C}$ for $12-16 \mathrm{~h}$ until exponential growth phase was achieved. Revived C. albicans cells were pooled by centrifugation at 3,000 $\times \mathrm{g}$. After two washing steps using sterile PBS (Punuosai Life-Tech Co., Wuhan, China), cells were resuspended in RPMI-1640 medium (LifeTechnologies Corporation, United States) and adjusted to a defined cell density using a hemocytometer prior to subsequent tests.

\section{Cell Culture}

A431 human vaginal epidermoid carcinoma cell line (Shanghai Cell Bank of the Chinese Academy of Sciences) was cultured at $37^{\circ} \mathrm{C}$ with $5 \% \mathrm{CO}_{2}$ in Dulbecco's Modified Eagle's Medium (Hyclone, United States) supplemented with $10 \%$ fetal bovine serum (Gibco, United States) and 1\% penicillin-streptomycin (Biyuntian Biotechnology Co., Ltd., Shanghai, China). At $24 \mathrm{~h}$ prior to experimentation, the culture medium was replaced with serum-free medium and maintained until cell harvest.

\section{Antifungal Assay}

The minimum inhibitory concentration (MIC) of BBR (Chengdu Munster Biotech Co., Ltd., China; purity: $98.38 \%$ by HPLC) against C. albicans SC5314 was evaluated in 96-well microplates (Corning, United States) using the broth microdilution method described by the Clinical and Laboratory Standard Institute (CLSI) M27-A3 document (CLSI, 2008) (Pierce et al., 2008). Initial yeast inoculum was adjusted to1-5× $10^{3} \mathrm{CFU} / \mathrm{ml}$ in PRMI-1640 medium buffered to $\mathrm{pH} 7.0$ with MOPS. The inoculum size was confirmed by plating serially diluted yeast-containing dilutions on Sabouraud agar 
plates. Each well that contains $100 \mu \mathrm{l}$ of yeast inoculum and a similar volume of two-fold diluted BBR $(16-1,024 \mu \mathrm{g} / \mathrm{ml})$ was incubated at $37^{\circ} \mathrm{C}$ for $48 \mathrm{~h}$. In addition, a drug-free control with fungal cells was included. Fluconazole was included as quality control. MIC of BBR was defined as the lowest drug concentration that caused no visible cell growth.

\section{XTT Reduction Assay}

XTT reduction assay was carried out to assess $C$. albicans viability. Briefly, in a 96-well plate, $100 \mu \mathrm{l}$ of $C$. albicans $(2 \times$ $\left.10^{6} \mathrm{CFU} / \mathrm{ml}\right)$ and $100 \mu \mathrm{l}$ of BBR $(32-256 \mu \mathrm{g} / \mathrm{ml})$ were added into each well and incubated at $37^{\circ} \mathrm{C}$ for 1,2 and $3 \mathrm{~h}$. Following two washing steps using sterile PBS, the OD value was detected by XTT reduction assay at $492 \mathrm{~nm}$ in a microplate reader (Manoharan et al., 2017; Rossoni et al., 2019).

\section{Cytotoxicity Test}

In order to detect the toxicity of BBR to A431 cells, we treated A431 cells $\left(2 \times 10^{5}\right.$ cells $\left./ \mathrm{ml}\right)$ with BBR at different concentrations. Cells were inoculated in 96-well plates and cultured at $37^{\circ} \mathrm{C}$ for $24 \mathrm{~h}$ before treatment with the same volume of BBR $(8-128 \mu \mathrm{g} /$ $\mathrm{ml}$ ). Finally, $10 \mu \mathrm{l}$ of CCK8 solution (Biyuntian Biotechnology Co., Ltd., Shanghai, China) was added into each well and incubated for $1 \mathrm{~h}$, and the absorbance of each well was measured at $450 \mathrm{~nm}$ using a microplate reader.

\section{Adhesion Test}

Gram staining, an established staining method for bacteria, was used to observe the adherence of $C$. albicans. Briefly, in a 6-well plate, $2 \mathrm{ml}$ of cells $\left(2 \times 10^{5}\right.$ cells $\left./ \mathrm{ml}\right)$ were cultured for $24 \mathrm{~h}$ at $37^{\circ} \mathrm{C}$ and $5 \% \mathrm{CO}_{2}$ before incubation with $C$. albicans diluted by the same volume of DMEM culture medium to different concentrations $\left(2 \times 10^{4}, 2 \times 10^{5}, 2 \times 10^{6}, 2 \times 10^{7}, 2 \times\right.$ $10^{8} \mathrm{CFU} / \mathrm{ml}$, respectively) for 1,2 and $3 \mathrm{~h}$. At designated time points, cells were fixed with $4 \%$ paraformaldehyde at room temperature for $15 \mathrm{~min}$, and washed 3 times with PBS. After that, enhanced Gram staining solution (Beijing Regen Biotechnology Co., Ltd., China) was applied. Finally, oil immersion lens (OLYMPUS BX51, Tokyo) was used for cell imaging.

\section{Cell Grouping and Berberine Intervention}

Gram staining was performed to evaluate the adherence of $C$. albicans with or without BBR treatment. Briefly, in a 6-well plate, $2 \mathrm{ml}$ of A431 cells $\left(2 \times 10^{5}\right.$ cells $\left./ \mathrm{ml}\right)$ were cultured for $24 \mathrm{~h}$ at $37^{\circ} \mathrm{C}$ and $5 \% \mathrm{CO}_{2}$, then the culture supernatant was removed. Cells receiving different treatments were grouped as follows: Blank group (A431 cells added in DMEM culture medium), Control group (A431 cells added in DMEM culture medium plus $C$. albicans), Treatment group (A431 cells added in DMEM culture medium plus C. albicans and BBR), Negative control group (A431 cells added in DMEM medium containing BBR without $C$. albicans). Cells were cultured at $37^{\circ} \mathrm{C}$ with $5 \% \mathrm{CO}_{2}$ for 1,2 and $3 \mathrm{~h}$. At corresponding time points, cells were fixed with $4 \%$ paraformaldehyde, followed by washing with PBS and staining with enhanced Gram staining solution. Finally, oil immersion lens (OLYMPUS BX51, Tokyo, Japan) was used for cell imaging.

\section{Scanning Electron Microscopy}

To further detect the adhesion of C. albicans to vaginal epithelial cells, samples of fungi-cells adhesion were prepared by using round cover slides (Bioshrp, China) in a 12-well plate for visualization using SEM. Cell grouping and BBR intervention were performed as described above. Samples were fixed by $2.5 \%$ glutaraldehyde overnight, and dehydrated by $30,50,70,90$, and $100 \%$ ethanol for $10 \mathrm{~min}$. Samples were air-dried before sputter coating with gold in a vacuum evaporator. Morphological observation and image acquisition were performed using SEM at $\times 2000$ magnification (SU8100, HITACHI, Japan).

\section{Immunofluorescence}

Calcofluor white (CFW) (Sigma, United States) was used to determine the adhesion of $C$. albicans to vaginal epithelial cells. Samples were prepared in 6-well plates as described above. Briefly, A431 cells were cultured for 1, 2, and $3 \mathrm{~h}$ after BBR treatment. At corresponding time points, cells were washed with sterile PBS before staining with $5 \%$ CFW $(1 \mathrm{mg} / \mathrm{ml})$ at room temperature for $10 \mathrm{~min}$. Cells were observed using DMI8 fluorescence microscope at $\times 200$ magnification (Leica, GER).

To further determine the possible role of intercellular adhesion molecule ICAM-1 in C. albicans adhesion to vaginal epithelial cells, cellular localization of expressed ICAM-1 was analyzed. Briefly, cell sample preparation was performed as described above, following which coverslips were taken out and washed 3 times with PBS. Cells were then fixed with $4 \%$ paraformaldehyde for $15 \mathrm{~min}$ and permeabilized with $0.5 \%$ Triton X-100 (Beijing Soleibao Company, China) for $30 \mathrm{~min}$ before blocking with 1\% BSA (Beijing Soleibao Company, China) for $1 \mathrm{~h}$. After 3 washing steps with PBS, cells were incubated with ICAM-1 primary antibody (1:200 diluted in $1 \%$ BSA) overnight at $4^{\circ} \mathrm{C}$, and then with FITC-conjugated Goat Anti-Rabbit IgG (Haul) secondary antibody (1:150 diluted in 1\% BSA) in the dark at room temperature for $1 \mathrm{~h}$. Finally, $50 \mu \mathrm{l}$ of anti-fluorescence attenuation sealing agent (including DAPI) (Beijing Soleibao Company, China) was added and incubated at room temperature in the dark for $20 \mathrm{~min}$ for cell imaging and quantification using a DMI8 inverted fluorescence microscope (Leica, GER).

\section{Western Blot}

Western blotting was performed to detect the expression of ICAM-1, mucin 1 and mucin4. At corresponding time points, culture medium was removed and cells were washed 6 times with PBS before harvest using a cell scraper. After treatment with protein extract solution containing protease inhibitor, total cell protein extract solution was centrifuged at $12,000 \mathrm{rpm}, 4^{\circ} \mathrm{C}$ for $5 \mathrm{~min}$. The protein concentration of cells in each treatment group was determined using BCA Protein Assay Kit. Proteins were separated by SDS-PAGE gel electrophoresis before being transferred onto PVDF membranes (Milipore, United States). Transferred membranes were blocked for $2 \mathrm{~h}$ in $5 \%$ non-fat dry milk in TBST before incubation overnight at $4^{\circ} \mathrm{C}$ with one of the following primary antibodies respectively: rabbit anti- $\beta$-actin (1: 5,000; Abbkine, United States), rabbit anti-ICAM-1 antibody (1: 1,000; Zhengneng Biotech Co., Chengdu, China), rabbit anti- 
A

C. albicans (1 h)

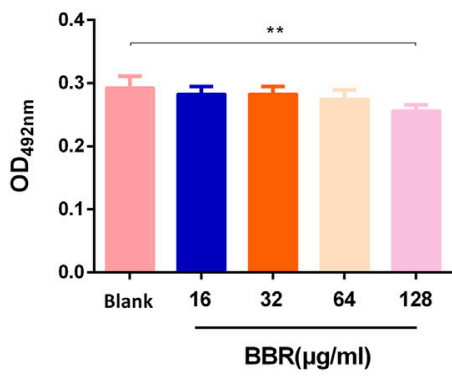

B

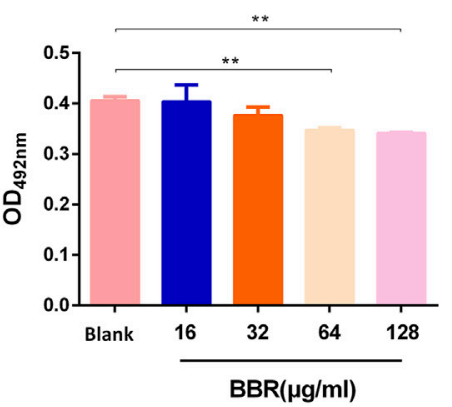

C

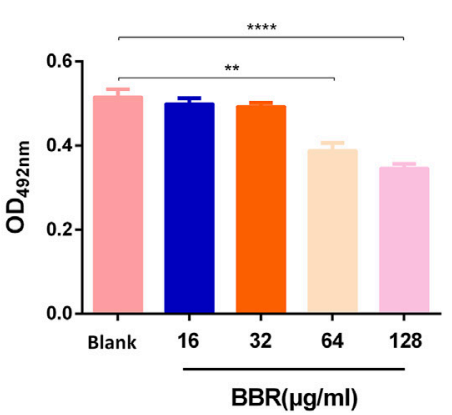

FIGURE 1 | Effect of different concentrations of BBR on the viability of $C$. albicans at (A) $1 \mathrm{~h}$ (B) $2 \mathrm{~h}$, and (C) $3 \mathrm{~h}$. The drug-free strain-containing medium was set as the Blank. The drug concentration of treatments was as follows: Blank, $16 \mu \mathrm{g} / \mathrm{ml} \mathrm{BBR,} 32 \mu \mathrm{g} / \mathrm{ml}$ BBR, $64 \mu \mathrm{g} / \mathrm{ml}$ BBR and $128 \mu \mathrm{g} / \mathrm{ml}$ BBR. Data are shown as mean \pm SD. ${ }^{\star *} p<0.01,{ }^{* * \star *} p<0.0001$ vs. compared with Blank.

Mucin-1 antibody (1:900; Boaosen Biotech Co., Beijing, China) and rabbit anti-Mucin-4 antibody (1:1,000; Zhengneng Biotech Co., Chengdu, China). After three 10-min washing steps with Tween20/TBS, the membranes were incubated with secondary antibody (1:10,000; Affinity, United States) at room temperature for $2 \mathrm{~h}$. After washing three times with Tween20/TBS, the membranes were treated with ECL reagent (Advansta, United States) and visualized using FluorChem M Imaging System (ProteinSimple, United States). Data were quantified by automated densitometry using ImageJ. Densitometric data were normalized against $\beta$-actin in triplicates.

\section{ELISA}

The levels of cytokines (IL-2 and IL-4) from vaginal epithelial cells were measured by enzyme-linked immunosorbent assay kit. Cell grouping and BBR treatment were performed as described above. At corresponding time points, cell culture supernatant was collected and the levels of IL- 2 and IL- 4 were analyzed by ELISA (ElabScience, Wuhan, China) according to manufacturer's instructions.

\section{Statistical Analysis}

Differences between experimental groups were assessed for significance using a two-tailed unpaired Student's $t$-test and Two-way ANOVA analysis with GraphPad Prism 5 software. All experiments were repeated at least three times. Data are expressed as mean \pm standard deviation and $p<0.05$ is considered to be statistically significant.

\section{RESULTS}

\section{Determination of the Minimum Inhibitory Concentration of Berberine on C. albicans}

To determine the inhibitory effect of BBR on C. albicans, the MIC of BBR against $C$. albicans SC5314 was examined. The MIC of BBR for this strain was $64 \mu \mathrm{g} / \mathrm{ml}$ according to the result of twofold dilution assay, and the MIC of fluconazole against C. albicans is $1 \mu \mathrm{g} / \mathrm{ml}$. To further investigate the effect of BBR on the viability of this strain, an XTT reduction assay was performed. After this strain was treated with different concentrations of BBR ranging from $32 \mu \mathrm{g} / \mathrm{ml}$ to $256 \mu \mathrm{g} / \mathrm{ml}$ for $1,2,3 \mathrm{~h}$, the OD value was measured at a wavelength of $492 \mathrm{~nm}$. Our results showed that this compound had no effects on the viability of C. albicans at the subinhibitory concentrations of 16 and $32 \mu \mathrm{g} / \mathrm{ml}$ (Figures 1A,B), while it could significantly reduce this fungal viability in a dose and time-dependent manner at concentrations higher than $32 \mu \mathrm{g} /$ $\mathrm{ml}$ (Figure 1C). Taken together, our findings indicate that although it shows a certain inhibitory effect at high concentrations, the inhibitory effect of BBR on the growth of C. albicans can be neglected when its concentration is lower than $32 \mu \mathrm{g} / \mathrm{ml}$.

\section{Determination of Toxicity of Berberine to Vaginal Epithelial Cells}

To determine the toxicity of this compound to vaginal epithelial cells, the viability of these cells after being treated with BBR at different doses and times was measured. The untreated cell group with a cell survival rate of $100 \%$ was used as a control for relative comparison. As shown in Figure 2A, there was no change in cell viability after treatment with $8-128 \mu \mathrm{g} / \mathrm{ml}$ BBR for $1 \mathrm{~h}$. However, when they were exposed to $128 \mu \mathrm{g} / \mathrm{ml} \mathrm{BBR}$ for $2 \mathrm{~h}$ (Figure $2 \mathrm{~B}$ ) or $3 \mathrm{~h}$ (Figure 2C) or $64 \mu \mathrm{g} / \mathrm{ml}$ for $3 \mathrm{~h}$ (Figure 2C), the viability of these cells was significantly reduced. Furthermore, when the cells were exposed to BBR for $24 \mathrm{~h}$, each dose group could show cytotoxicity (Figure 2D). The above results indicate that the cell survival rate is related to the time and concentration of the compound BBR to treat the cells. For this reason, $32 \mu \mathrm{g} / \mathrm{ml}$ was determined as the appropriate concentration of BBR in the following adhesion experiment.

\section{Optimal Dose of C. albicans for Adhesion to Vaginal Epithelial Cells}

To explore the appropriate condition of the adhesion of $C$. albicans to vaginal epithelial cells, the concentration of $C$. albicans and the exposure time of A431 cells to C. albicans 

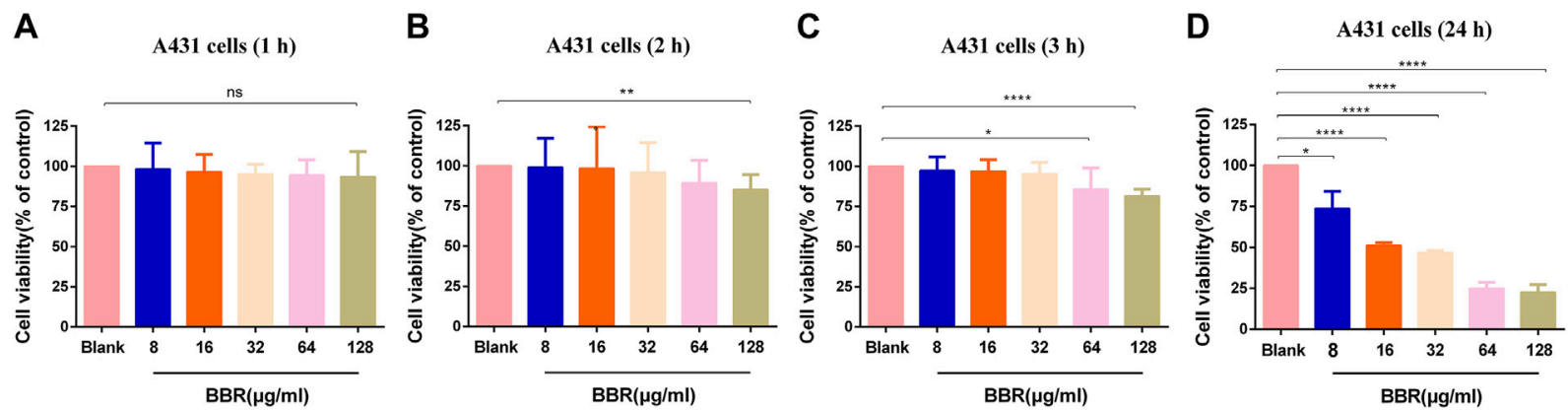

FIGURE 2| Effect of different concentrations of BBR on the viability of A431 cells at (A) $1 \mathrm{~h}$ (B) $2 \mathrm{~h}$ (C) $3 \mathrm{~h}$, and (D) $24 \mathrm{~h}$. The drug-free cell-containing medium was set as the Blank. The drug concentration of treatments was as follows: Blank, $8 \mu \mathrm{g} / \mathrm{ml} \mathrm{BBR,} 16 \mu \mathrm{g} / \mathrm{ml} \mathrm{BBR,} 32 \mu \mathrm{g} / \mathrm{ml} \mathrm{BBR}, 64 \mu \mathrm{g} / \mathrm{ml}$ BBR and $128 \mu \mathrm{g} / \mathrm{ml}$ BBR. Data are shown as mean \pm SD. ${ }^{\star} p<0.05,{ }^{* \star} p<0.01,{ }^{\star \star \star *} p<0.0001$. vs. compared with Blank.
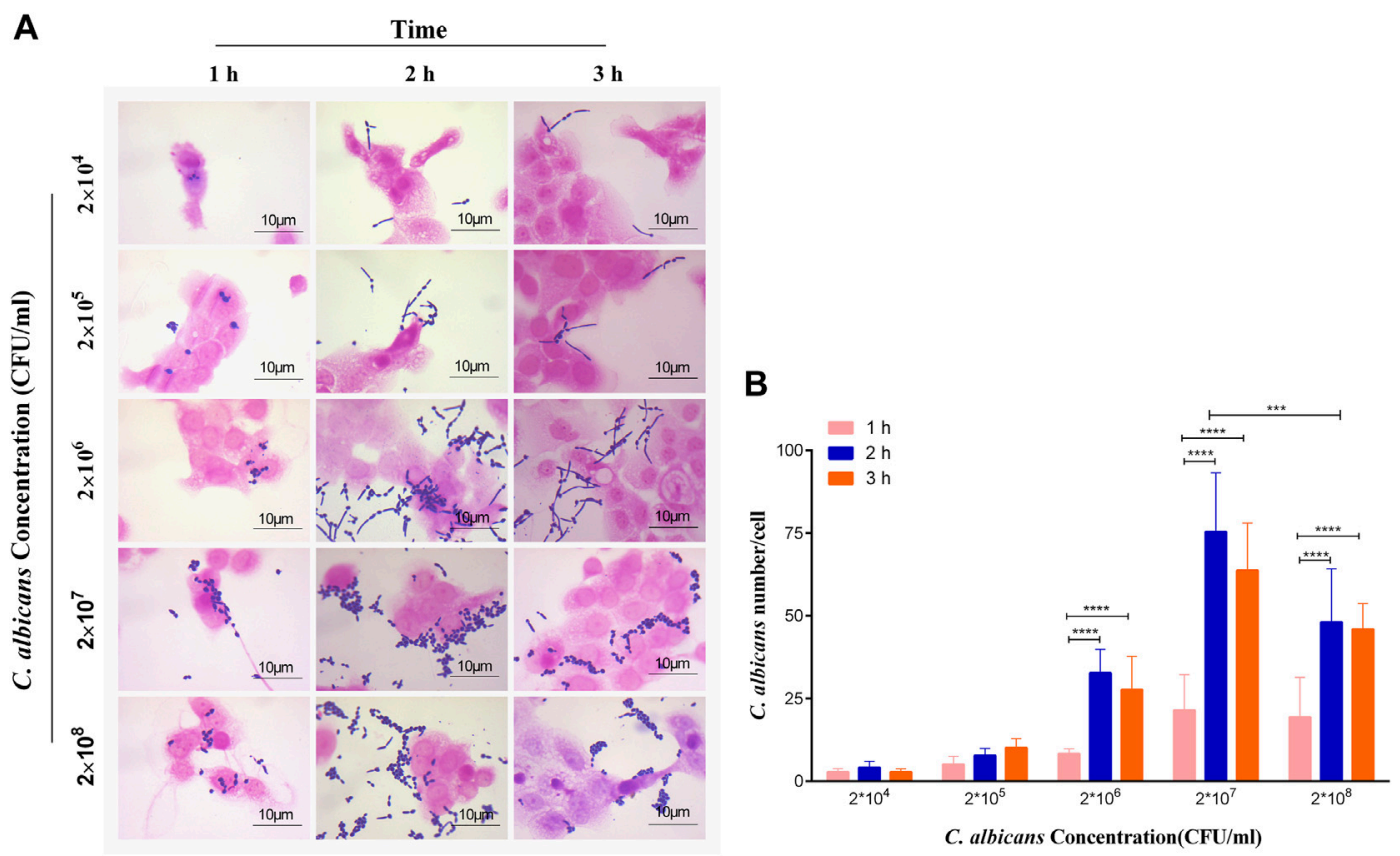

FIGURE 3 | (A) Observation and (B) quantification of different concentrations of $C$. albicans on its adherence to A431 cells at 1,2 and 3 h, respectively. ${ }^{\star * \star *} p<$ 0.0001. vs. $1 \mathrm{~h}$ group. Scale bar, $10 \mu \mathrm{m}$.

were considered as two crucial factors. The results were measured by the Gram staining. As shown in Figure 3A, the adhered number of yeasts to A431 cells increased with the increase of $C$. albicans concentrations from $2 \times 10^{4}$ to $2 \times 10^{7} \mathrm{CFU} / \mathrm{ml}$, while the adhesion capability significantly reduced when the concentration of this fungi increased to $2 \times 10^{8} \mathrm{CFU} / \mathrm{ml}$. On the other hand, there were no significant differences for the adhesion capability of C. albicans to vaginal epithelial cells at different exposure times $(1,2$ and $3 \mathrm{~h})$ when the concentration of $C$. albicans was $2 \times 10^{4}$ to $2 \times 10^{5} \mathrm{CFU} / \mathrm{ml}$ (Figure 3B). However, the adhesion capability significantly increased with the increase of exposure time when the concentration of $C$. albicans increased to $2 \times 10^{7} \mathrm{CFU} / \mathrm{ml}$, in which the adhesion number of $C$. albicans to cells peaked with a mean of 75 C. albicans per cell (Figure 3B). Therefore, $2 \times$ $10^{7} \mathrm{CFU} / \mathrm{ml}$ was considered to be the adhesion concentration of C. albicans.

\section{Effect of Berberine on the Adhesion of $C$. albicans to Vaginal Epithelial Cells}

To determine the inhibitory effect of BBR on the adhesion of $C$. albicans to vaginal epithelial cells, $32 \mu \mathrm{g} / \mathrm{ml}$ BBR and $2 \times$ $10^{7} \mathrm{CFU} / \mathrm{ml} \mathrm{C}$. albicans were added into $2 \times 10^{5}$ A431cells in a 6-well plate. After treatment with different exposure time, the plate was stained by the Gram staining assay. As shown in Figure 4A, compared with the control, the adhesion number 

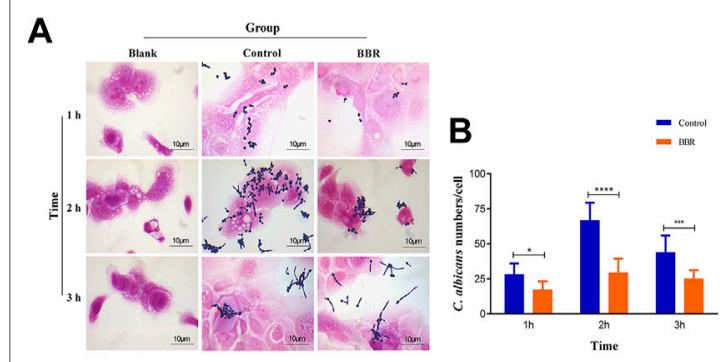

C
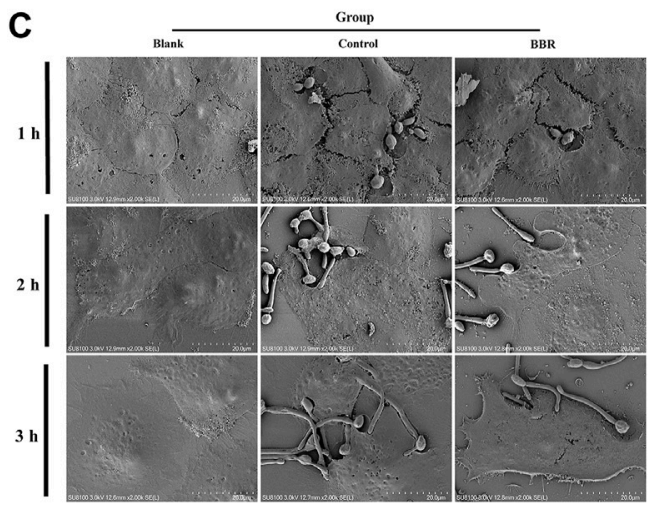

D
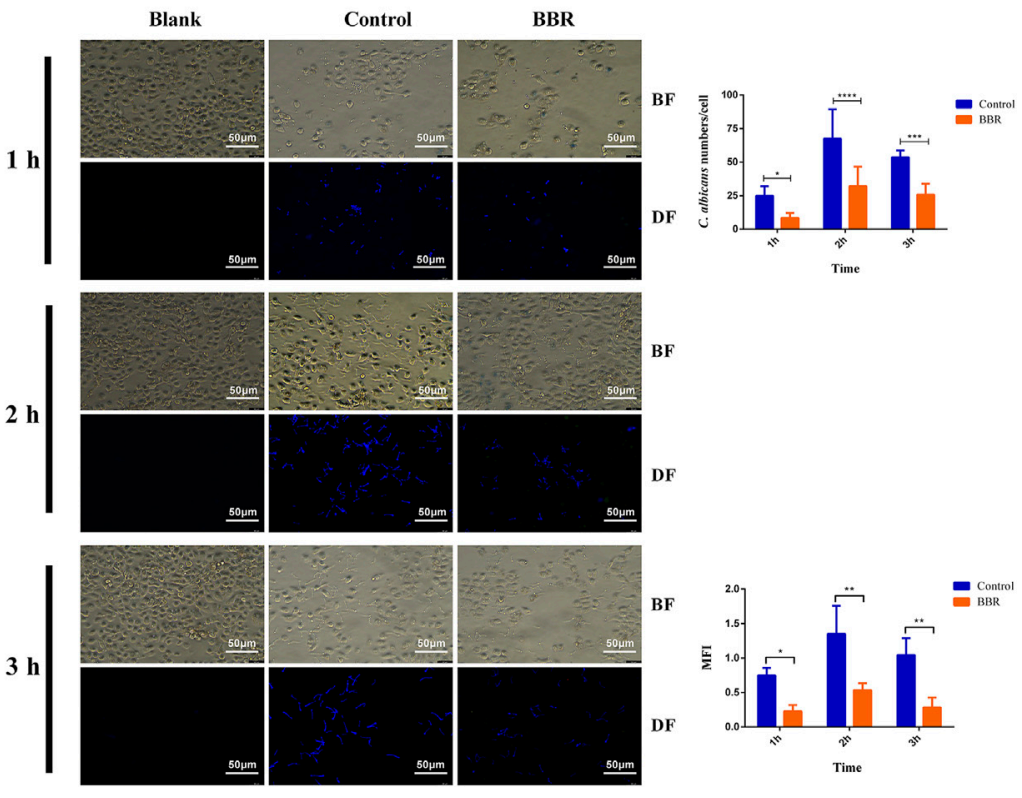

FIGURE 4 | (A) Light microscopy image, and (B) quantification (C) SEM images and (D) Fluorescent images, quantification of $C$. albicans numbers adhered to A431 cells and quantification of mean fluorescence intensity of $C$. albicans numbers adhered to A431cells in the Blank, Control, and BBR(32 $\mu \mathrm{g} / \mathrm{ml})$ groups at $1,2,3 \mathrm{~h}$, respectively. BF: Bright field, DF: Dark field; ${ }^{\star} p<0.05,{ }^{\star \star} p<0.01,{ }^{\star \star \star} p<0.001,{ }^{\star \star \star \star} p<0.0001$. vs. Control group. Scale bar, $10 \mu \mathrm{m}$ (A), $20 \mu \mathrm{m}$ (C) and $50 \mu \mathrm{m}$ (D)

of C. albicans treated with BBR significantly reduced. It is worth noting that the inhibitory effect of BBR on adhesion of C. albicans to A431 cells was time-dependent. Compared with $1 \mathrm{~h}$, the inhibitory effect on adhesion of $C$. albicans to cells was much stronger after treatment with BBR for $2-3 \mathrm{~h}$ (Figure 4B). To further observe the inhibitory effect of BBR, the adhesion of $C$. albicans after BBR treatment was visualized by SEM. A similar result with the Gram staining assay was obtained (Figure 4C).

Furthermore, CFW staining was used to evaluate the inhibitory effect of BBR on adhesion of C. albicans to A431 cells. The adhesion number of $C$. albicans was counted and the mean fluorescence intensity (MFI) was determined under an inverted fluorescence microscope. As shown in Figure 4D, compared with the control, the adhesion number (right-up panel) and MFI (right-low panel) of C. albicans to A431 cells in the group treated with BBR significantly decreased. Also, a stronger inhibitory effect was observed after treatment with BBR for 2 or $3 \mathrm{~h}$, which is similar to the result of the Gram staining assay. Taken together, our data revealed that BBR may play an important role in regulation of adhesion of C. albicans to vaginal epithelial cells.

\section{The Expression of ICAM-1, mucin1, and mucin4 in Vaginal Epithelial Cells Exposed to C. albicans Reduced After Treatment With Berberine}

The adhesion of C. albicans to vaginal epithelial cells involves a complex interaction between the fungi and the cells, which depends not only on the ligands on the surface of C. albicans, but also on receptors or adhesion molecules on the surface of host cells. ICAM-1, a cell adhesion molecule, is known to mediate the adhesion of $C$. albicans to vaginal epithelial cells (Youn et al., 2008). To explore the detailed mechanisms that BBR regulates the adhesion of $C$. albicans to vaginal epithelial cells, the expression of ICAM-1 in the A431 cells exposed to C. albicans was detected after treatment with BBR. As shown in Figure 5A, compared with A431 cells without any treatment, $C$. albicans could strongly induce the expression of ICAM-1 in A431 cells in a timedependent manner of $C$. albicans exposure, while its expression significantly reduced after treatment with $\mathrm{BBR}(p<$ 0.01 ), which indicates BBR may regulate the adhesion of $C$. albicans to vaginal epithelial cells by blocking ICAM-1. To further verify this regulation, the A431 cells exposed to $C$. albicans were performed an immunofluorescence (IF) analysis after treatment with or without BBR. A similar result was obtained. The IF analysis visualized that the expression of ICAM-1 in the A431 cells exposed to C. albicans was significantly higher than that in the A431 cells without $C$. albicans infection with the increase of $C$. albicans adhesion time, while its expression was significantly decreased after treatment with BBR (Figures 5D,E; $p<0.0001$ ).

Mucin 1 and Mucin 4 are another two important molecules that mediate the adhesion of pathogens to vaginal epithelial cells (Moncla et al., 2016). To further verify our finding that BBR can block adhesion of $C$. albicans to vaginal epithelial cells, the expressions of mucin 1 and mucin 4 were detected by Western blot. Our results showed that the expression levels of mucin 1 and 

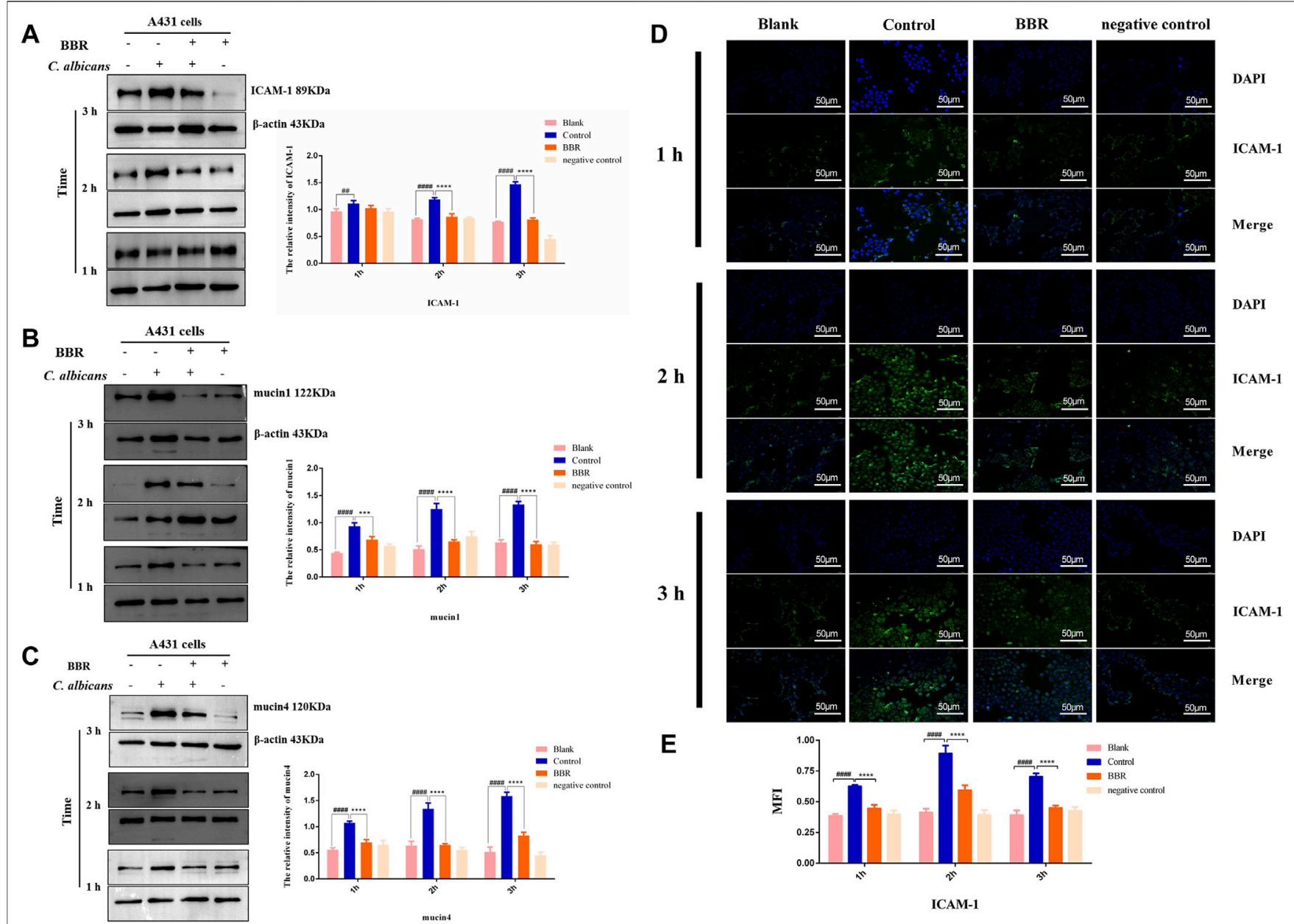

FIGURE 5 | Western blot and quantification of the expression levels of (A) ICAM-1 (B) mucin1 and (C) mucin4 in A431 cells of the Blank, Control, BBR(32 $\mu$ g/ml) and negative control groups at 1, 2, $3 \mathrm{~h}$, respectively. (D) Observation and (B) quantification of BBR on the expression of adhesion molecule ICAM-1 in A431 cells stimulated by C. albicans at 1, 2, 3 h, respectively. \#\#p $<0.01$, \#\#\#\#p<0.0001. vs. Blank group; ${ }^{\star \star \star} p<0.001,{ }^{\star \star \star \star} p<0.0001$. vs. Control group. Scale bar, $50 \mu$ m.

mucin4 in the A431 cells exposed to C. albicans significantly increased in a time-dependent manner of $C$. albicans exposure (Figures 5B,C; $p<0.01$ ). After treatment with BBR, however, the expression of mucin 1 and mucin 4 in these cells exposed to $C$. albicans significantly decreased, indicating that BBR may block adhesion of $C$. albicans by regulating the expression of mucin 1 and mucin 4 .

Taken together, our findings indicate BBR may block the adhesion of $C$. albicans to vaginal epithelial cells by modulating ICAM-1, mucin1, and mucin4.

\section{The Balance of IL-2 and IL-4 Was Rebuilt After Treatment With Berberine in Vaginal Epithelial Cells Exposed to C. albicans}

When VVC occurs, C. albicans often induces vaginal epithelial cells to produce a large number of cytokines, including proinflammatory factors and anti-inflammatory factors, in which IL2 and IL-4 are considered as the representative of proinflammatory and anti-inflammatory members, respectively.
During VVC pathogenesis, the local immune homeostasis of the vagina is often broken. To explore whether the effect of the compound BBR on the local immune homeostasis of the vagina, the levels of IL-2 and IL-4 in A431 cells exposed to $C$. albicans were measured by ELISA assay after treatment with BBR. Our results showed that the levels of IL-2 and IL-4 in A431 cells exposed to $C$. albicans were significantly higher compared with those from A431 cells without $C$. albicans exposure $(p<0.05)$, indicating the local homeostasis of vagina can be broken by $C$. albicans exposure. In the presence of BBR, however, the level of IL-2 significantly decreased and the level of IL- 4 was significantly increased (Figure 6; $p<0.01$ ). It is worth noting that exposure time of A431 cells to C. albicans could affect the expression of IL2 and IL-4. With extension of exposure time to C. albicans, the level of IL- 2 secreted by A431 cells significantly increased, while the level of IL-4 significantly decreased (Table 1).

The ratio of IL- 2 and IL- 4 is usually considered as a balance of locally vaginal homeostasis. For this reason, the ratio of IL-2/IL-4 in A431 cells exposed to C. albicans was calculated after treatment with or without BBR. Our results showed that the proportion of 

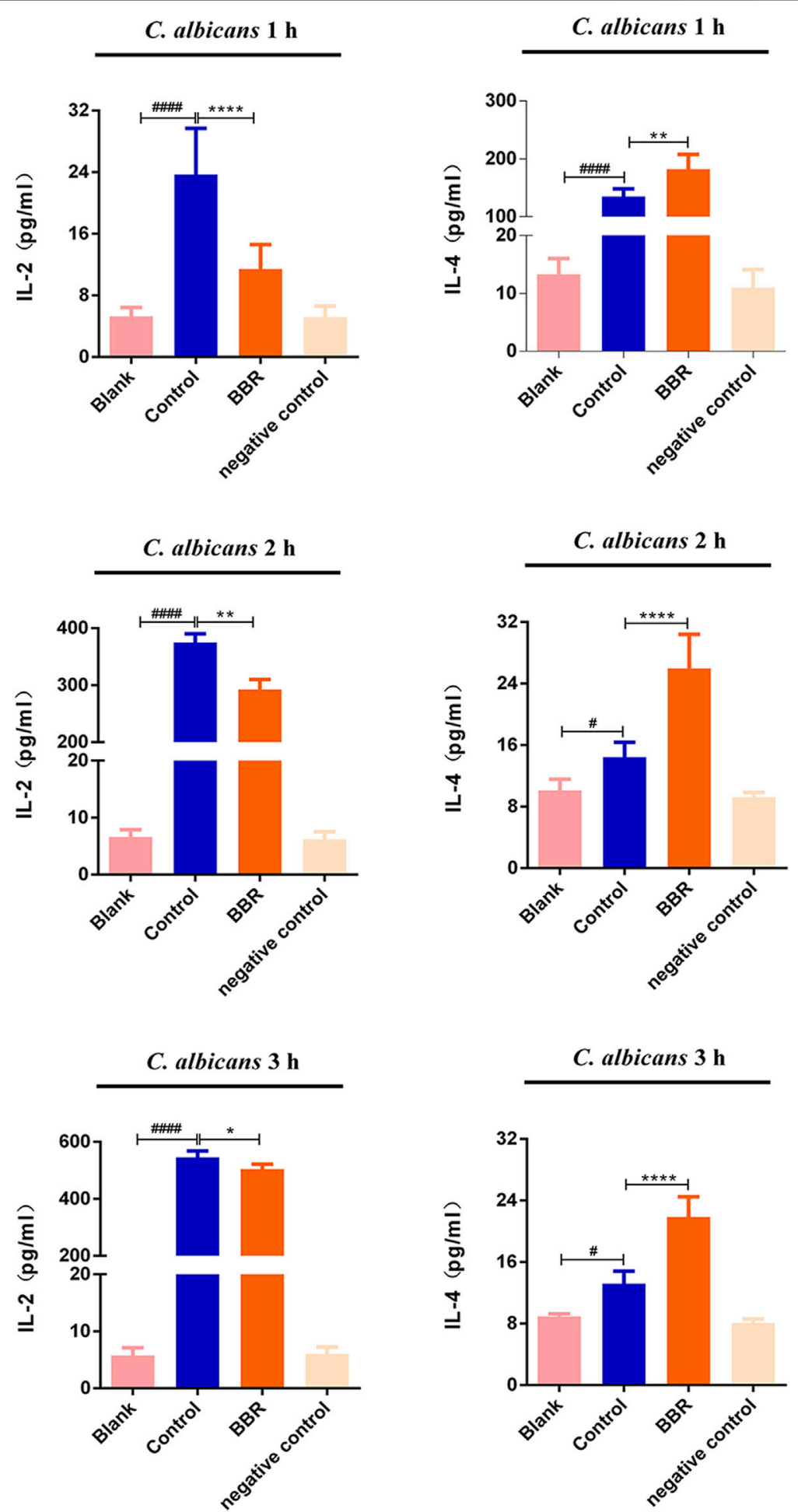

FIGURE 6 | The levels of IL-2 and IL-4 in the Blank, Control, BBR(32 $\mu \mathrm{g} / \mathrm{ml})$ and negative control groups at $1 \mathrm{~h}$ (upper), $2 \mathrm{~h}$ (middle)and $3 \mathrm{~h}$ (lower), respectively.

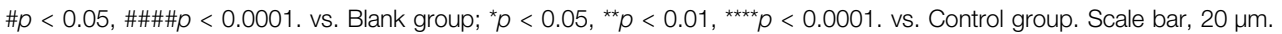

IL-2/IL-4 in A431 cells exposed to C. albicans significantly increased with the extension of exposure time (Table $1 ; p<$ 0.001 ), while it is worth noting that the increase in the ratio of IL-
2/IL-4 was much smaller after treatment with BBR. At the same time point, the proportion of IL-2/IL-4 in A431 cells exposed to C. albicans after treatment with BBR was significantly lower than 
TABLE 1 | IL-2/LL-4 ratios.

\begin{tabular}{|c|c|c|c|c|c|c|c|}
\hline Time & Cytokine (pg/ml) & Blank & Control & BBR & Negative control & $F$-value & $p$-value \\
\hline- & $\mathrm{IL}-2$ & $5.28 \pm 1.16$ & $23.70 \pm 5.98$ & $11.42 \pm 3.17$ & $5.19 \pm 1.44$ & 24.667 & $<0.0001^{a}$ \\
\hline $1 \mathrm{~h}$ & $\mathrm{IL}-4$ & $13.27 \pm 2.75$ & $134.77 \pm 13.20$ & $182.15 \pm 25.49$ & $10.98 \pm 3.11$ & 142.872 & $<0.0001^{a}$ \\
\hline- & IL-2/IL-4 & $0.40 \pm 0.03$ & $0.18 \pm 0.06$ & $0.06 \pm 0.03$ & $0.51 \pm 0.24$ & 10.747 & $<0.0001$ \\
\hline- & $\mathrm{IL}-2$ & $6.61 \pm 1.26$ & $374.81 \pm 15.44$ & $292.50 \pm 17.69$ & $6.17 \pm 1.35$ & $1,062.304$ & $<0.0001^{a}$ \\
\hline $2 \mathrm{~h}$ & IL-4 & $10.12 \pm 1.44$ & $14.43 \pm 11.94$ & $25.96 \pm 4.44$ & $9.21 \pm 0.64$ & 36.494 & $<0.0001^{\mathrm{a}}$ \\
\hline- & IL-2/IL-4 & $0.65 \pm 0.05$ & $26.28 \pm 3.10$ & $11.45 \pm 1.61$ & $0.67 \pm 0.15$ & 192.569 & $<0.0001^{a}$ \\
\hline- & $\mathrm{IL}-2$ & $5.75 \pm 1.36$ & $545.62 \pm 22.22$ & $504.24 \pm 17.79$ & $6.04 \pm 1.24$ & 1771.245 & $<0.0001^{a}$ \\
\hline $3 h$ & IL-4 & $8.91 \pm 0.34$ & $13.18 \pm 1.65$ & $20.22 \pm 3.53$ & $8.69 \pm 1.25$ & 27.597 & $<0.0001^{a}$ \\
\hline- & IL-2/IL-4 & $0.64 \pm 0.14$ & $41.82 \pm 4.69$ & $25.65 \pm 5.57$ & $0.71 \pm 0.22$ & 123.031 & $<0.0001^{a}$ \\
\hline
\end{tabular}

${ }^{a} p<0.0001$.
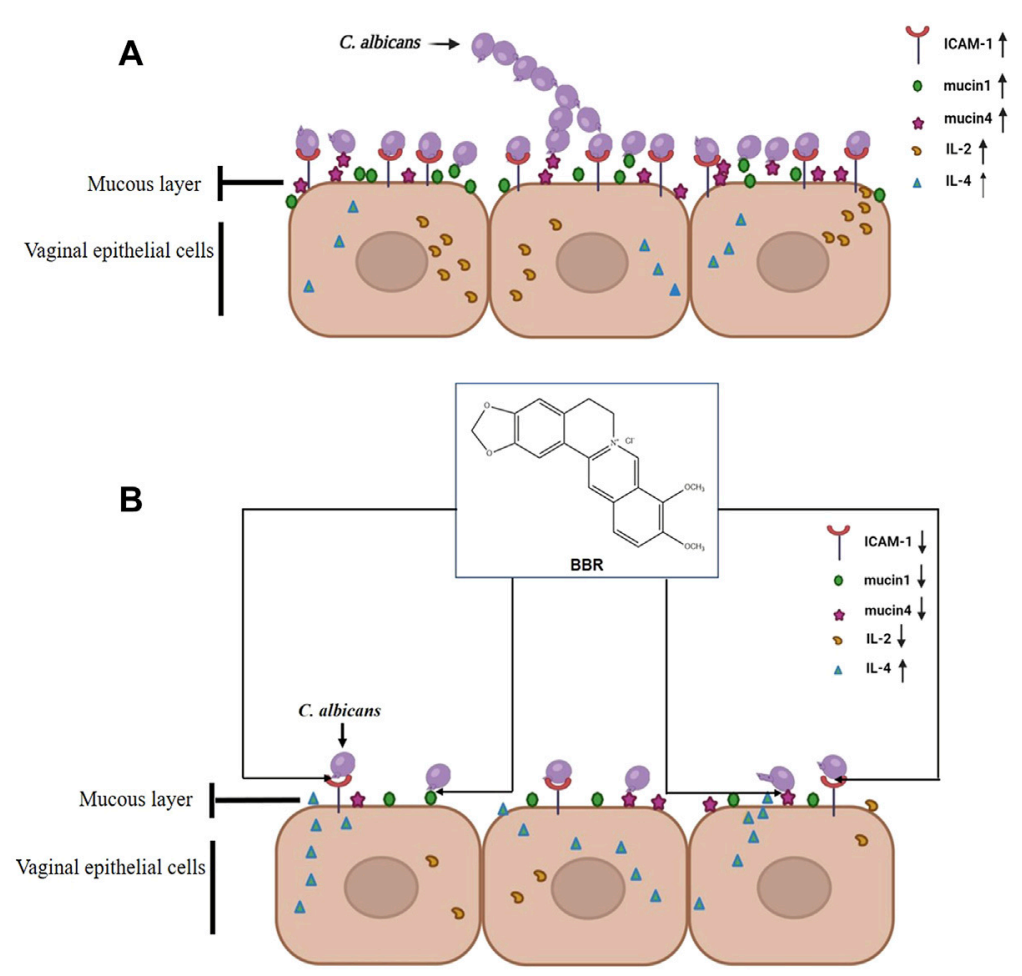

FIGURE 7|Possible mechanism of BBR blocking the adhesion of $C$. albicans to vaginal epithelial cells by inhibiting the expression of cell adhesion molecule ICAM1, mucin1 and mucin4.

that in A431 cells only exposed to C. albicans without BBR treatment (Table 1; $p<0.001$ ), indicating BBR could regulate the locally vaginal homeostasis by balancing the level of IL-2 and IL-4.

\section{DISCUSSIONS}

In this study, our data shows that BBR plays a key role in preventing the adhesion of $C$. albicans to vaginal epithelial cells. The expression of adhesion-associated molecules, such as ICAM-1, mucin1, and mucin4 significantly increased in vaginal epithelial cells when challenged with C. albicans, while they dramatically decreased after treatment of BBR. Consistently, the adhesion number of $C$. albicans to vaginal epithelial cells significantly decreased. The expression of pro-inflammatory cytokine IL-2 and anti-inflammatory cytokine IL-4 was regulated by this compound. A new immune homeostasis was rebuilt again. The inflammatory pathogenesis of vaginal epithelial cells was significantly improved. Thus, all of the data included in this paper imply that BBR could play an essential role in controlling infection of $C$. albicans during VVC pathogenesis through its effects on adhesion and regulation of immune barrier. Also, our study provides an alternatively potential strategy to develop new VVC therapy agents with relatively low toxicity from natural herbs (Figure 7). 
Vulvovaginal candidiasis (VVC) is a mucosal immune inflammatory disease caused by $C$. albicans infection in the vagina due to pathogen-host interaction. Höfs and others found that some virulence factors of $C$. albicans such as candidalysin, Sap, and LP may play an important role in the development of VVC (Höfs et al., 2016). However, the effects of these virulence factors depend to a large extent on the interaction between pathogen and the host. It is required for $C$. albicans to establish infection that $C$. albicans adheres to vaginal epithelial cells. This adhesion is a complex interaction that involves a variety of signal molecules, including pathogen ligands, especially, pathogen-associated molecular pattern (PAMP), receptors, or adhesion molecules of host cells (Gilmore et al., 1988; Moyes et al., 2015). The adhesion-associated molecules such as ICAM-1, mucin-1, and mucin-4 are often highly expressed in vaginal epithelial cells following exposure to some pathogens, including C. albicans (Youn et al., 2008; Hinderfeld and Simoes-Barbosa 2020). ICAM-1 is an endothelial- and leukocyte-associated transmembrane protein whose main function is to stabilize the interaction between cells and promote the migration of leukocytes and endothelial cells (Lyck and Enzmann 2015; Bui et al., 2020). More recently, ICAM-1 has been characterized as a site for the epithelial adherance of fungi (Egusa et al., 2005; Mikamo et al., 2018). Because of these associations with immune responses, it has been considered as a pro-inflammatory factor that participates in inflammatory leukocyte recruitment and activation, and endothelial cell injury by signaling through cascades involving a number of kinases (Luo et al., 2020). ICAM-1 ligation enhances the adhesion of $C$. albicans to human vaginal epithelial cells (Mikamo et al., 2018). In this study, our data shows that ICAM-1 in vaginal epithelial cell line A431 increases during the exposure to $C$. albicans. Consistently, the adhesion number of C. albicans to cells also significantly increased. This suggests that the interaction between ICAM-1 on vaginal epithelial cell and its ligands from $C$. albicans could be a crucial step for the opportunistic infection caused by C. albicans. Thus, blocking this adhesion of C. albicans to vaginal epithelial cells may be a prospective strategy for the treatment of VVC. Of note, biofilm formation is recognized as an important virulence factor of C. albicans, which is responsible for chronic or recurrent infection, especially in catheter-related infection. More recently, the two groups had reported that BBR could inhibit the formation of C. albicans biofilms (Huang et al., 2020; Xie et al., 2020). Therefore, we did not repeat the experiment with BBR combating C. albicans biofilm in this study. In addition, the role of $C$. albicans biofilms in the pathogenesis of VVC is controversial, and Swidsinski A and others argued against the effects of $C$. albicans biofilms in VVC (Swidsinski et al., 2019). Taken together, the present study did not perform biofilm assay.

Mucins have been found to have important functions in defense against fungal infections, which exhibit unique gel properties that facilitate the mucus layer to adhere permanently to the epithelial cells, thereby protecting the epithelial cells from the invasion of fungi (Linford 1974; Zhao et al., 2020). Recently, mucins are considered as a biomarker of infectious vaginal diseases when they are excessively produced
(Hinderfeld and Simoes-Barbosa 2020). As the classical members of the mucin family, mucin-1 and mucin- 4 have been reported to have important biological functions on cell-cell and cellextracellular matrix interactions, cell signal transduction, and cell carcinogenesis. Our previous results have shown that these two molecules are highly expressed in the vaginal mucosa of mice during VVC pathogenesis, and then significantly decreased after treatment with the extract of Pulsatilla chinensis (Bunge) Regel [Ranunculales] decoction (Zhao et al., 2020). Consistent with this result, our data showed that mucin-1 and mucin-4 were transiently highly expressed in vaginal epithelial cells in a time-dependent manner at the beginning of $C$. albicans adhesion; however, their expression was significantly reduced after BBR intervention. This reduction may be due to the fact that the compound BBR decreases ICAM-1 in the vaginal epithelial cells exposed to $C$. albicans, initiates a cascade reaction, and thereby activating a signal pathway.

$\mathrm{BBR}$, a natural isoquinoline alkaloid with low toxicity, has been used for thousands of years to treat gastrointestinal diseases in China. However, in recent years, plenty of studies have shown that this compound has a wide spectrum of biochemical and pharmacological effects and it has been applied clinically in an attempt to combat some diseases such as diabetes, cancer, Alzheimer's disease. Multiple mechanisms could be involved. For example, Liu and others confirm that BBR can prevent primary peritoneal adhesion and the adhesion reformation by directly inhibiting TIMP-1 in rats (Liu et al., 2020). However, Zhang and others find that this compound not only prevents post-surgery intestinal adhesion by down-regulating ICAM-1, but it also reduces inflammation by inhibiting the TAK1/JNK and TAK1/NF- $\kappa B$ signaling in rats (Zhang et al., 2014). Furthermore, studies also finds that it can protect the kidneys of diabetic nephropathy rats (Tang et al., 2016) and attenuate monocyte adhesion to endothelial cells induced by oxidized low-density lipoprotein by down-regulating ICAM-1 (Huang et al., 2013). In this study, we found that BBR has the minimal toxicity to vaginal epithelial cell line A431 at the concentration of $32 \mu \mathrm{g} / \mathrm{ml}$ and significantly inhibits the adhesion of $C$. albicans to these cells. Western blot further visualizes BBR significantly reduces the expression of ICAM-1in these cells, indicating that BBR could block the adhesion of $C$. albicans to vaginal epithelial cells mainly by modulating the expression ICAM-1, although this compound has a certain degree of antimicrobial effect. Besides, we also notice that this compound can down-regulate the expression level of mucins, suggesting that it could have the protection of vaginal epithelial cells from C. albicans invasion. This protective effect was also confirmed in the study of bacterial infections that BBR can inhibit bacterial adhesion and inflammation through decreasing mucin expression via the NF- $\mathrm{BB}$ signaling pathway, thereby protecting IPEC-J2 cells from enterotoxigenic Escherichia coli (ETEC) infection (Liu et al., 2019).

When infection occurs, lymphocytes and some immunerelated cells such as epithelial cells often need to maintain a balance between type 1 and type 2 immunity to control the progress of the infection (Spellberg and Edwards 2001). It is wellknown that IL-2 and IL-4, respectively, are the classical members of Type 1 and type 2 immunity. They play a crucial role in the 
regulation of local mucosal immunity. Therefore, correcting the imbalance of IL-2 and IL-4 caused by fungal infection may contribute to the restoration of local immune homeostasis. Baofukang suppository, a traditional Chinese medicine, has been shown to improve the clinical symptoms in VVC patients. In vitro experiments have observed that this medication can resume the $C$. albicans-triggered imbalanced ratio of IL-2/IL-4 cytokines to normal, resulting in the decrease of pro-inflammatory cytokine IL-2 and the increase of anti-inflammatory cytokine IL-4 (Li et al., 2016). Further, Lin and others confirmed that BBR down-regulates ratios of the relative IL-2/IL-4 cytokines expression fold in mouse primary splenocytes in the absence or presence of LPS in a preventive manner, suggesting that BBR may possess anti-inflammatory potential by shifting the Th1/Th2 balance toward Th2 polarization Lin and Lin, 2011. In this study, we observed that, following the exposure of C. albicans to vaginal epithelial cells, the expression of IL-2 is gradually increased, and IL-4 also increased. This increase could aim to counteract instinctively the effects of IL-2 at the very early stage of C. albicans. However, after treatment with BBR, IL-2 gradually decreased, while IL-4 gradually increased, indicating that BBR could play an important role in correcting cytokine imbalance during the pathogenesis of VVC.

\section{CONCLUSION}

In this study, our data showed that BBR can decrease the adhesion of C. albicans and act as a potential therapeutic agent for VVC by inhibiting the expression of ICAM-1, mucin1, and mucin4, as well as alleviating inflammatory injury in vaginal epithelial cells

\section{REFERENCES}

Bui, T. M., Wiesolek, H. L., and Sumagin, R. (2020). ICAM-1: A Master Regulator of Cellular Responses in Inflammation, Injury Resolution, and Tumorigenesis. J. Leukoc. Biol. 108, 787-799. doi:10.1002/JLB.2MR0220-549R

Egusa, H., Nikawa, H., Makihira, S., Jewett, A., Yatani, H., and Hamada, T. (2005). Intercellular Adhesion Molecule 1-dependent Activation of Interleukin 8 Expression in Candida Albicans-Infected Human Gingival Epithelial Cells. Infect. Immun. 73, 622-626. doi:10.1128/IAI.73.1.622-626.2005

Eschenauer, G. A., Nguyen, M. H., and Clancy, C. J. (2015). Is Fluconazole or an Echinocandin the Agent of Choice for Candidemia. Ann. Pharmacother. 49 (9), 1068-1074. doi:10.1177/1060028015590838

Gilmore, B. J., Retsinas, E. M., Lorenz, J. S., and Hostetter, M. K. (1988). An iC3b Receptor on Candida Albicans: Structure, Function, and Correlates for Pathogenicity. J. Infect. Dis. 157, 38-46. doi:10.1093/infdis/157.1.38

Hinderfeld, A. S., and Simoes-Barbosa, A. (2020). Vaginal Dysbiotic Bacteria Act as Pathobionts of the Protozoal Pathogen Trichomonas Vaginalis. Microb. Pathog. 138, 103820. doi:10.1016/j.micpath.2019.103820

Höfs, S., Mogavero, S., and Hube, B. (2016). Interaction of Candida Albicans with Host Cells: Virulence Factors, Host Defense, Escape Strategies, and the Microbiota. J. Microbiol. 54, 149-169. doi:10.1007/s12275-016-5514-0

Huang, X., Zheng, M., Yi, Y., Patel, A., Song, Z., and Li, Y. (2020). Inhibition of Berberine Hydrochloride on Candida Albicans Biofilm Formation. Biotechnol. Lett. 42, 2263-2269. doi:10.1007/s10529-020-02938-6

Huang, Z., Cai, X., Li, S., Zhou, H., Chu, M., Shan, P., et al. (2013). Berberineattenuated M-onocyte A-dhesion to E-ndothelial C-ells I-nduced by O-xidized by down-regulating the expression of IL-2 and by up-regulating the expression of IL-4.

\section{DATA AVAILABILITY STATEMENT}

The raw data supporting the conclusions of this article will be made available by the authors, without undue reservation.

\section{AUTHOR CONTRIBUTIONS}

TW and CW conceived and designed the study. TZ and CW wrote the manuscript. GS, KM, and BW critically reviewed the manuscript and provided general advice. TZ, KZ, and JS performed the experiments and analyzed the data. All authors have read and agreed to the published version of the manuscript.

\section{FUNDING}

The research was funded by the National Natural Science Foundation of China (Grant Nos. 81774034, 81573725), and Natural Science Key Project of Anhui Institution of Higher Education (KJ 2021A0590, KJ 2020A0387).

\section{ACKNOWLEDGMENTS}

The authors would like to express their gratitude to EditSprings (https://www.editsprings.com/) for the expert linguistic services provided.

L-ow-density L-ipoprotein via I-nhibition of A-dhesion M-olecule E-xpression. Mol. Med. Rep. 7, 461-465. doi:10.3892/mmr.2012.1236

Krachler, A. M., and Orth, K. (2013). Targeting the Bacteria-Host Interface: Strategies in Anti-adhesion Therapy. Virulence 4, 284-294. doi:10.4161/viru. 24606

Li, T., Niu, X., Zhang, X., Wang, S., and Liu, Z. (2016). Baofukang Suppository Promotes the Repair of Vaginal Epithelial Cells in Response to Candida Albicans. AMB Express 6, 109. doi:10.1186/s13568-016-0281-1

Li, X., Zhao, S. J., Shi, H. L., Qiu, S. P., Xie, J. Q., Wu, H., et al. (2014). Berberine Hydrochloride IL-8 Dependently Inhibits Invasion and IL-8-independently Promotes Cell Apoptosis in MDA-MB-231 Cells. Oncol. Rep. 32, 2777-2788. doi:10.3892/or.2014.3520

Lin, W. C., and Lin, J. Y. (2011). Berberine Down-Regulates the Th1/Th2 Cytokine Gene Expression Ratio in Mouse Primary Splenocytes in the Absence or Presence of Lipopolysaccharide in a Preventive Manner. Int. Immunopharmacol 11 (12), 1984-1990. doi:10.1016/j.intimp.2011.08.008

Linford, E. (1974). Cervical Mucus: an Agent or a Barrier to conception? J. Reprod. Fertil. 37, 239-250. doi:10.1530/jrf.0.0370239

Liu, X., Liu, F., Ma, Y., Li, H., Ju, X., and Xu, J. (2019). Effect of Puerarin, Baicalin and Berberine Hydrochloride on the Regulation of IPEC-J2 Cells Infected with Enterotoxigenic Escherichia coli. Evid. Based Complement. Alternat. Med. 2019, 7438593. doi:10.1155/2019/7438593

Liu, X., Wei, Y., Bai, X., Li, M., Li, H., Wang, L., et al. (2020). Berberine Prevents Primary Peritoneal Adhesion and Adhesion Reformation by Directly Inhibiting TIMP-1. Acta Pharm. Sin. B. 10, 812-824. doi:10.1016/j.apsb.2020.02.003

Luan, T., Liu, X., Mao, P., Wang, X., Rui, C., Yan, L., et al. (2020). The Role of 17ßEstrogen in Candida Albicans Adhesion on Human Vaginal Epithelial Cells via 
FAK Phosphorylation. Mycopathologia 185, 425-438. doi:10.1007/s11046-02000440-1

Luo, S. F., Chin, C. Y., Ho, L. J., Tseng, W. Y., Kuo, C. F., and Lai, J. H. (2020). Monosodium Urate Crystals Induced ICAM-1 Expression and Cell-Cell Adhesion in Renal Mesangial Cells: Implications for the Pathogenesis of Gouty Nephropathy. J. Microbiol. Immunol. Infect. 53, 23-32. doi:10.1016/j. jmii.2017.12.004

Lyck, R., and Enzmann, G. (2015). The Physiological Roles of ICAM-1 and ICAM2 in Neutrophil Migration into Tissues. Curr. Opin. Hematol. 22, 53-59. doi:10. 1097/MOH.0000000000000103

Maiolo, E. M., Furustrand Tafin, U., Borens, O., and Trampuz, A. (2014). Activities of Fluconazole, Caspofungin, Anidulafungin, and Amphotericin B on Planktonic and Biofilm Candida Species Determined by Microcalorimetry. Antimicrob. Agents Chemother. 58 (5), 2709-2717. doi:10.1128/AAC.00057-14

Manoharan, R. K., Lee, J. H., Kim, Y. G., Kim, S. I., and Lee, J. (2017). Inhibitory Effects of the Essential Oils $\alpha$-longipinene and Linalool on Biofilm Formation and Hyphal Growth of Candida Albicans. Biofouling 33, 143-155. doi:10.1080/ 08927014.2017.1280731

Martin, H., Govern, M. M., Abbey, L., Gilroy, A., Mullins, S., Howell, S., et al. (2018). Inhibition of Adherence of the Yeast Candida Albicans to Buccal Epithelial Cells by Synthetic Aromatic Glycoconjugates. Eur. J. Med. Chem. 160, 82-93. doi:10.1016/j.ejmech.2018.10.011

Mayer, F. L., Wilson, D., and Hube, B. (2013). Candida Albicans Pathogenicity Mechanisms. Virulence 4, 119-128. doi:10.4161/viru.22913

Mikamo, H., Yamagishi, Y., Sugiyama, H., Sadakata, H., Miyazaki, S., Sano, T., et al. (2018). High Glucose-Mediated Overexpression of ICAM-1 in Human Vaginal Epithelial Cells Increases Adhesion of Candida Albicans. J. Obstet. Gynaecol. 38, 226-230. doi:10.1080/01443615.2017.1343810

Moncla, B. J., Chappell, C. A., Debo, B. M., and Meyn, L. A. (2016). The Effects of Hormones and Vaginal Microflora on the Glycome of the Female Genital Tract: Cervical-Vaginal Fluid. PloS one 11, e0158687. doi:10.1371/journal.pone. 0158687

Moyes, D. L., Richardson, J. P., and Naglik, J. R. (2015). Candida AlbicansEpithelial Interactions and Pathogenicity Mechanisms: Scratching the Surface. Virulence 6, 338-346. doi:10.1080/21505594.2015.1012981

Pesee, S., Angkananuwat, C., Tancharoensukjit, S., Muanmai, S., Sirivan, P., Bubphawas, M., et al. (2016). In Vitro activity of Caspofungin Combined with Fluconazole on Mixed Candida Albicans and Candida Glabrata Biofilm. Med. Mycol. 54 (4), 384-393. doi:10.1093/mmy/myv108

Pierce, C. G., Uppuluri, P., Tristan, A. R., Wormley, F. L., Mowat, E., Ramage, G., et al. (2008). A Simple and Reproducible 96-well Plate-Based Method for the Formation of Fungal Biofilms and its Application to Antifungal Susceptibility Testing. Nat. Protoc. 3, 1494-1500. doi:10.1038/nport.2008.141

Pirillo, A., and Catapano, A. L. (2015). Berberine, a Plant Alkaloid with Lipid- and Glucose-Lowering Properties: From In vitro Evidence to Clinical Studies. Atherosclerosis 243, 449-461. doi:10.1016/j.atherosclerosis.2015.09.032

Richardson, J. P., Moyes, D. L., Ho, J., and Naglik, J. R. (2019). Candida Innate Immunity at the Mucosa. Semin. Cel Dev. Biol. 89, 58-70. doi:10.1016/j.semcdb. 2018.02.026

Richardson, J. P., Willems, H. M. E., Moyes, D. L., Shoaie, S., Barker, K. S., Tan, S. L., et al. (2018). Candidalysin Drives Epithelial Signaling, Neutrophil Recruitment, and Immunopathology at the Vaginal Mucosa. Infect. Immun. 86, e00645. doi:10.1128/IAI.00645-17

Rossoni, R. D., de Barros, P. P., Lopes, L. A. D. C., Ribeiro, F. C., Nakatsuka, T., Kasaba, H., et al. (2019). Effects of Surface Pre-reacted Glass-Ionomer (S-PRG) Eluate on Candida spp.: Antifungal Activity, Anti-biofilm Properties, and Protective Effects on Galleria Mellonella against C. Albicans Infection. Biofouling 35, 997-1006. doi:10.1080/08927014.2019.1686485

Sobel, J. D., and Sobel, R. (2018). Current Treatment Options for Vulvovaginal Candidiasis Caused by Azole-Resistant Candida Species. Expert Opin. Pharmacother. 19, 971-977. doi:10.1080/14656566.2018.1476490
Spellberg, B., and Edwards, J. E., Jr. (2001). Type 1/Type 2 Immunity in Infectious Diseases. Clin. Infect. Dis. 32, 76-102. doi:10.1086/317537

Swidsinski, A., Guschin, A., Tang, Q., Dörffel, Y., Verstraelen, H., Tertychnyy, A., et al. (2019). Vulvovaginal Candidiasis: Histologic Lesions Are Primarily Polymicrobial and Invasive and Do Not Contain Biofilms. Am. J. Obstet. Gynecol. 220 (1), 91. doi:10.1016/j.ajog.2018.10.023

Tang, L. Q., Ni, W. J., Cai, M., Ding, H. H., Liu, S., and Zhang, S. T. (2016). Renoprotective Effects of Berberine and its Potential Effect on the Expression of $\beta$-arrestins and Intercellular Adhesion Molecule-1 and Vascular Cell Adhesion Molecule-1 in Streptozocin-Diabetic Nephropathy Rats. J. Diabetes 8, 693-700. doi:10.1111/1753-0407.12349

Wang, X., Feng, S., Ding, N., He, Y., Li, C., Li, M., et al. (2018). Anti-Inflammatory Effects of Berberine Hydrochloride in an LPS-Induced Murine Model of Mastitis. Evid. Based Complement. Alternat. Med. 2018, 5164314. doi:10. $1155 / 2018 / 5164314$

Willems, H. M. E., Ahmed, S. S., Liu, J., Xu, Z., and Peters, B. M. (2020). Vulvovaginal Candidiasis: A Current Understanding and Burning Questions. J. Fungi (Basel) 6, 27. doi:10.3390/jof6010027

Wu, J., Wu, D., Zhao, Y., Si, Y., Mei, L., Shao, J., et al. (2020). Sodium New Houttuyfonate Inhibits Candida Albicans Biofilm Formation by Inhibiting the Ras1-cAMP-Efg1 Pathway Revealed by RNA-Seq. Front. Microbiol. 11, 2075. doi: $10.3389 /$ fmicb. 2020.02075

Xie, Y., Liu, X., and Zhou, P. (2020). In Vitro Antifungal Effects of Berberine against Candida Spp. In Planktonic and Biofilm Conditions. Drug Des. Devel Ther. 14, 87-101. doi:10.2147/DDDT.S230857

Yang, Y., Wang, Y. D., Wang, Y., Xu, Z. Q., Wu, D. Q., Wang, T. M., et al. (2021). Effect of Berberine Hydrochloride on Cell wall Integrity of Candida Albicans Hypha. Zhongguo Zhong Yao Za Zhi 46, 155-161. doi:10.19540/j.cnki.cjcmm. 20200907.401

Youn, H., Hong, K., Yoo, J. W., and Lee, C. H. (2008). ICAM-1 Expression in Vaginal Cells as a Potential Biomarker for Inflammatory Response. Biomarkers 13, 257-269. doi:10.1080/13547500701843338

Zhang, H., Wei, J., Xue, R., Wu, J. D., Zhao, W., Wang, Z. Z., et al. (2010). Berberine Lowers Blood Glucose in Type 2 Diabetes Mellitus Patients through Increasing Insulin Receptor Expression. Metabolism 59, 285-292. doi:10.1016/j.metabol. 2009.07.029

Zhang, Y., Li, X., Zhang, Q., Li, J., Ju, J., Du, N., et al. (2014). Berberine Hydrochloride Prevents Postsurgery Intestinal Adhesion and Inflammation in Rats. J. Pharmacol. Exp. Ther. 349 (3), 417-426. doi:10.1124/jpet.114.212795

Zhao, T., Wang, Y. D., Zhang, K., Zhang, M. X., Duan, Q. J., Wang, T. M., et al. (2020). Effect of Butyl Alcohol Extract of Baitouweng Decoction on Epithelial Barrier of Vaginal Mucosa in Mice with Vulvovaginal Candidiasis. China J. Chin. Materia Med. 45, 4991-4996. doi:10.19540/j.cnki.cjcmm.20200618.401

Conflict of Interest: The authors declare that the research was conducted in the absence of any commercial or financial relationships that could be construed as a potential conflict of interest.

Publisher's Note: All claims expressed in this article are solely those of the authors and do not necessarily represent those of their affiliated organizations, or those of the publisher, the editors and the reviewers. Any product that may be evaluated in this article, or claim that may be made by its manufacturer, is not guaranteed or endorsed by the publisher.

Copyright $\odot 2022$ Zhao, Zhang, Shi, Ma, Wang, Shao, Wang and Wang. This is an open-access article distributed under the terms of the Creative Commons Attribution License (CC BY). The use, distribution or reproduction in other forums is permitted, provided the original author(s) and the copyright owner(s) are credited and that the original publication in this journal is cited, in accordance with accepted academic practice. No use, distribution or reproduction is permitted which does not comply with these terms. 